\title{
Case Report \\ Cord Blood Platelet Gel as a Treatment of Occipital Pressure Injuries in Newborns: Report of Two Cases
}

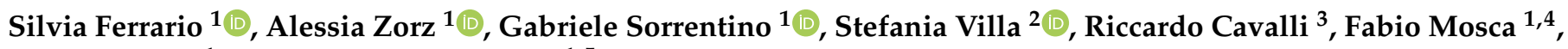 \\ Laura Plevani ${ }^{1}$ and Stefano Ghirardello ${ }^{1,5, *}$
}

1 Neonatal Intensive Care Unit, Foundation IRCCS Ca' Granda Ospedale Maggiore Policlinico, Via della Commenda 12, 20122 Milan, Italy; silvia.ferrario@policlinico.mi.it (S.F.); alessia.zorz@policlinico.mi.it (A.Z.); gabriele.sorrentino@policlinico.mi.it (G.S.); fabio.mosca@policlinico.mi.it (F.M.); laura.plevani@policlinico.mi.it (L.P.)

2 Department of Transfusion Medicine and Hematology, Foundation IRCCS Ca' Granda Ospedale Maggiore Policlinico, Via Francesco Sforza 35, 20122 Milan, Italy; stefania.villa@policlinico.mi.it

3 Pediatric Dermatology Unit, Foundation IRCCS Ca' Granda Ospedale Maggiore Policlinico, Via Pace, 9 , 20122 Milan, Italy; riccardo.cavalli@policlinico.mi.it

4 Department of Clinical Sciences and Community Health, University of Milan, Via Festa del Perdono 7, 20122 Milan, Italy

5 Neonatal Intensive Care Unit, Foundation IRCCS Policlinico San Matteo, Piazzale Golgi 11, 27100 Pavia, Italy

* Correspondence: s.ghirardello@smatteo.pv.it; Tel.: +39-0382-502518; Fax: +39-0382-502477

Citation: Ferrario, S.; Zorz, A.; Sorrentino, G.; Villa, S.; Cavalli, R.; Mosca, F.; Plevani, L.; Ghirardello, S. Cord Blood Platelet Gel as a Treatment of Occipital Pressure Injuries in Newborns: Report of Two Cases. Children 2021, 8, 1079. https:// doi.org/10.3390/children8121079

Academic Editor: Nahla Zaghloul

Received: 29 October 2021

Accepted: 19 November 2021

Published: 23 November 2021

Publisher's Note: MDPI stays neutral with regard to jurisdictional claims in published maps and institutional affiliations.

Copyright: (C) 2021 by the authors. Licensee MDPI, Basel, Switzerland. This article is an open access article distributed under the terms and conditions of the Creative Commons Attribution (CC BY) license (https:/ / creativecommons.org/licenses/by/ $4.0 /)$.

\begin{abstract}
Background: A Pressure Ulcer (PU) is a severe event and could create discomfort to newborns. In newborns, one of mostly stricken location by PU is occipital area. Recent studies have highlighted that Cord Blood Platelet Gel (CBPG) might be a better alternative compared to traditional treatment. We report two cases of occipital PU treated with CBPG. Case report: Two male infants showing occipital PU were treated with standard local treatment, but no improvement was observed. After parental informed consent was obtained, CBPG application on PU was performed every $48 \mathrm{~h}$. In these two cases of PU, a fast improvement in healing was observed since the first application of CBPG. The PU healed resulted in a scar after 53 and 50 days (Case 1 and Case 2, respectively) from development. No complications or infections were reported. Conclusions: CBPG contains many angiogenetic and growth factors, these characteristics make it indicated in treating soft tissue injuries. It would seem to be safe and an effective treatment of neonatal PUs reducing the time of the healing and the hospitalization and the infectious risks. Further studies are needed to evaluate long term aesthetic and functional results of PU treated with CBPG.
\end{abstract}

Keywords: cord blood platelet gel; pressure injuries; newborn; case report

\section{Introduction}

Pressure ulcers (PU) are rarely reported in the neonatal population, with an estimated incidence in infants admitted to Neonatal Intensive Care Units (NICU) between 3.7\% and $21.6 \%$ and a prevalence of $23 \%$ [1].

Endotracheal tube, non-invasive ventilation, vascular catheter, immobilization, hypotension, hypoxemia, prolonged NICU hospitalization, low birth weight, and prematurity represent risk factors for PU [1-3].

Generally, PU can be subdivided in conventional, due to pressure over bones prominence, or device-related, produced by pressure of a diagnostic or therapeutic device [4].

Conventional PU require a longer time to develop than device-related PU and are more common in infants with higher birth weight [4]. Occiput is the area at higher risk for developing conventional PU; indeed, the head is proportionately larger and heavier than the body $[5,6]$.

A PU is a severe event associated with pain, worse sleep quality, neurobehavioral development, increased length of hospitalization, and increased risk of infection and 
toxicity due to treatment product absorption [2]. PU prevention and treatment are not standardized for the neonatal population and mainly refer to adults' experience. However, most of the available products to treat PU are contra-indicated in newborns because of the risk of absorption and toxicity. Therefore, only a few products are available for the treatment of neonatal PU [1].

In the last few years, platelet gel (PG) derived from peripheral blood (autologous or allogenic) has been proposed to treat PU, due to its properties. Indeed, PG can stimulate and accelerate wound healing, reduce bleeding, and promote tissue regeneration and angiogenesis. In addition, it might have an anti-inflammatory, analgesic, and anti-bacterial effect [7-11].

A platelet gel derived from cord blood (CBPG) was recently obtained and used in regenerative medicine [12-14].

Our group has previously described the positive experience with CBPG, used in infants affected by dystrophic recessive epidermolysis bullosa [15-17].

CBPG in use contains a mean platelet count of 1000 , range 800 to $1200 \times 10^{9} / \mathrm{L}$. CBPG is rich in growth factors such as platelet-derived growth factor, transforming growth factor, basic fibroblast growth factor, and vascular endothelial growth factor [18].

We describe the case of two newborns with occipital PU treated with CBPG, after the failure of conventional treatment.

\section{Case Presentations}

\subsection{Case 1}

Patient Information

A male infant affected by left-side congenital diaphragmatic hernia and treated with Fetoscopic Tracheal Occlusion (FETO) was born in June 2019 at $32+0$ weeks of gestational age by cesarean section, his birth weight was $1800 \mathrm{~g}$. He was immediately intubated at birth and transferred to the NICU. On day 2, he underwent surgical repair of the diaphragmatic breech with a Gore-Tex patch positioning. He required 33 days of mechanical ventilation and 21 days of non-invasive respiratory support (nasal continuous positive air pressure and high flow nasal cannula). Dobutamine, dopamine, milrinone, noradrenaline, and nitric oxide were administered in the first days after birth to correct systemic hypotension and pulmonary hypertension. Morphine and midazolam were administered for sedo-analgesia. After 19 days, an occipital PU developed.

At that time, the ulcer was classified "unstageable" by National Pressure Injury Advisory Panel (NPIAP) scale because it was covered by eschar [19]. Standard local treatment with thin hydrocolloid dressing was performed for 8 days without benefits. Then, the ulcer was classified as stage IV of NPIAP and its size was $1.8 \mathrm{~cm} \times 1.8 \mathrm{~cm}$. On day 27 of life, after having obtained the parents informed consent form, CBPG was locally administered to improve tissue repair and the healing process. The area was cleaned with a sterile physiological solution, and CBPG was aseptically placed on the ulcer. CBPG was covered with a non-woven fabric gauze. CBPG was applied every $48 \mathrm{~h}$; eight applications were necessary to significantly reduce the ulcer. Standard local treatment with hydrogel and thin hydrocolloid dressing was applied until complete resolution healing on day 72 (Figure 1). 

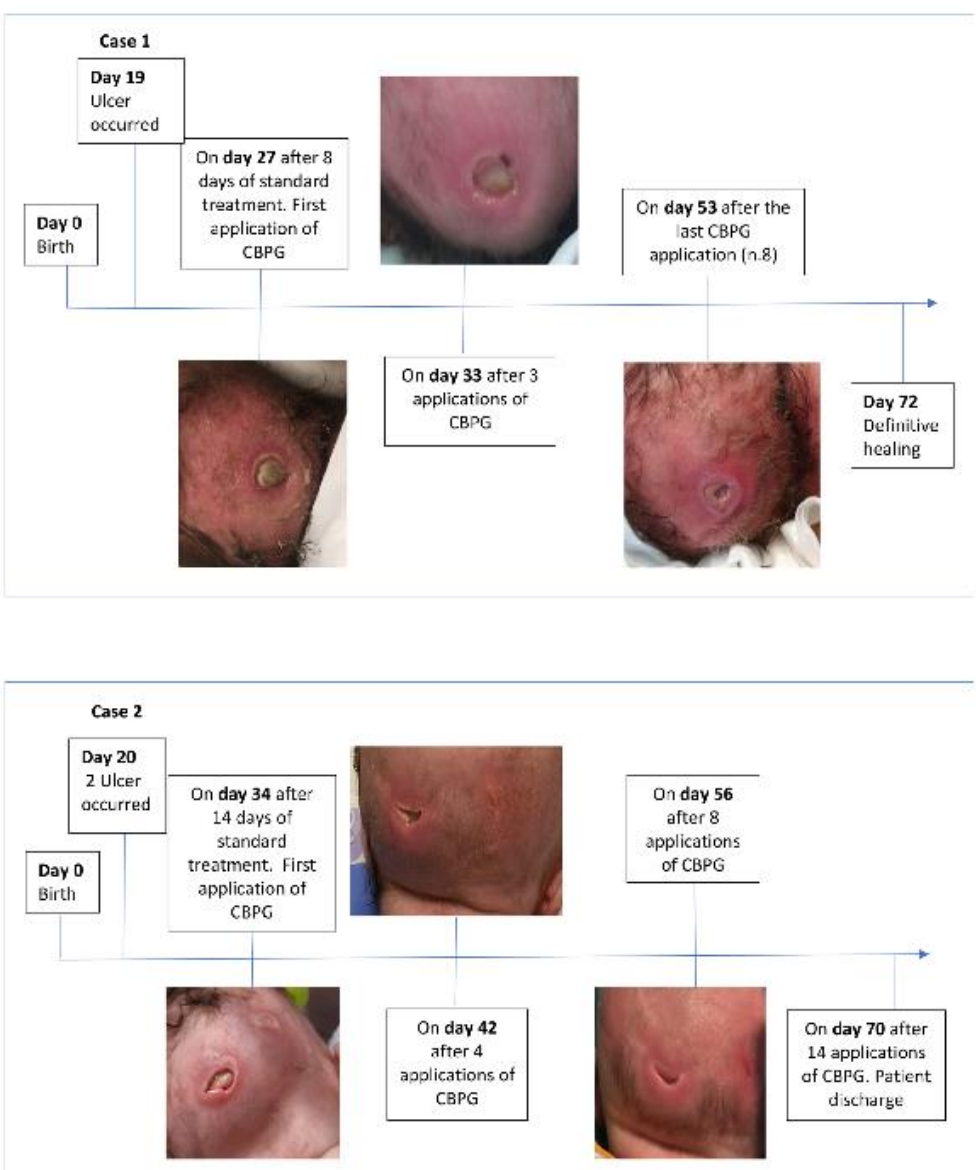

Figure 1. Case 1 and Case 2 timeline: from the development of PU to the definitive healing.

\subsection{Case 2}

Patient Information

A male infant affected by a cervical region's giant cystic lymphangioma was born in October 2020 at $38+6$ weeks of gestational age by EXIT procedure. Birth-weight was $2740 \mathrm{~g}$. He was immediately intubated and transferred to the NICU. On days 14 and 21, ultrasoundguided injections of sclerosing drugs (Doxycycline + Bleomycin) was performed to reduce the lesion, and administration of oral Sirolimus was started. On day 33, he was successfully extubated by video laryngoscopy procedure. On day 20, two occipital pressure ulcers developed due to deep sedation immobility and drug therapies.

Both ulcers were classified "unstageable" by NPIAP scale at the onset and were covered by eschar [19]. Standard local treatments with hydrogel and thin hydrocolloid dressing was started on the same day. No improvement was observed after 14 days of treatment, and both ulcers turned to stage IV of NPIAP; the sizes were $2 \mathrm{~cm} \times 1.5 \mathrm{~cm}$ and $0.7 \mathrm{~cm} \times 0.7 \mathrm{~cm}$, respectively. After having achieved the parental informed consent form, on day $34 \mathrm{CBPG}$ therapy was started. The portion of occiput was rinsed with sterile physiological solution and CBPG was applied on the ulcers using aseptic technique. CBPG was covered by an occlusive dressing of gauzes with paraffin and transparent film dressing. The smaller lesion was fully recovered after one application of CBPG. Fourteen applications were necessary to obtain final healing on day 70 (Figure 1).

\subsection{CBPG Preparation}

CBPG units were obtained after centrifugation of allogeneic cord blood units collected from placentas voluntarily donated to the Milano Cord Blood Bank by healthy mothers in term pregnancies, after informed consent, as previously described [20]. After sample collection, platelet gel was prepared by the centrifugation of cord blood unit. The bags 
containing the platelet concentrate were stored in a $-80{ }^{\circ} \mathrm{C}$ freezer and when necessary for use, under aseptic conditions, the bags were defrosted in a warm water bath at $37^{\circ} \mathrm{C}$. The platelet concentrate was activated with commercial activator kit Plateltex ${ }^{\circledR}$ ACT (Plateltex S.R.O., Prague, Czech Republic) following manufacturer's instructions. After mixing the platelet concentrate aliquots with activator $(9: 1)$ by gentle agitation at $22{ }^{\circ} \mathrm{C}\left( \pm 2{ }^{\circ} \mathrm{C}\right)$ for about $10 \mathrm{~min}$, the gelation occurs spontaneously [21].

\section{Discussion}

PG obtained from adult peripheral blood is currently used in dental, orthopedic, ophthalmic and cardiac surgery, bone, muscle, tendon, skin repair, and diabetic foot ulcer treatment [7]. PG contains growth factors that promote tissue regeneration and have antiinflammatory, anti-bacterial, analgesic, and hemostatic effects. PG obtained from discarded placentas (CBPG) has been used in pediatric settings in recent years [20].

CBPG shows immunomodulatory and tissue regenerative characteristics [22]. CBPG has a high level of viral safety; indeed, it is virtually Cytomegalovirus and Toxoplasma free [18].

Compared to that obtained from peripheral blood, CBPG contains different proteins, angiogenetic and growth factors, and hormones supporting fetal tissue formation; for these characteristics, CBPG is considered more effective in treating soft tissue injuries $[12,18,22]$.

Hospitalized newborns should be carefully evaluated for the risk of developing PU and a complete inspection of the skin should be performed, paying attention to the highrisk areas. The occiput is one of the most common areas of neonatal PU. Immobility, sedation, hypotension, hypoxemia, mechanical ventilation, and extracorporeal membrane oxygenation are risk factors for occipital PU. Postural changes are recommended for occipital PU prevention and treatment every two hours, and therapeutic surfaces are suggested $[1,23]$.

The treatment of neonatal PU is not standardized. There are fewer products available in the neonatal setting than in the adult population due to the increased risk of toxicity and adverse reactions. The neonatal population's standard PU treatment is based on the reduction in local pressure and cleaning the affected area with a sterile physiological solution. The products to use should be chosen based on therapeutic goals: debridement, exudate or infection management, or healing stimulation. Available products are hydrogel, hydrocolloid, polyurethane foam, hydrofiber, silicone, silver, transparent semipermeable dressing [2].

In partial-thickness PU, the cutis regenerates, the damaged skin regains original characteristics due to the re-epithelialization process, epithelial cells migrate from borders to the middle of the lesion. Therefore, the deepest portion of the epidermis is characterized by big stem cells whose division replaces the lost cells in the most superficial portion of the cutis.

In full-thickness PU, the cutis does not regenerate but just repairs damage, therefore, newly formed tissue does not regain original characteristics. In fact, granulation tissue grows from the base of a wound and fills the ulcer, resulting in scar tissue without skin appendages, e.g., hair follicles, sebaceous, and sweat glands localized in derma [24].

Our local standard treatment for unstageable and IV stage PU consists of cleaning the lesion with a sterile physiological solution followed by local hydrogel application to fill the PU and hydrocolloid dressing for autolytic debridement.

Specifically, in the two patients described, we started standard treatment according to our local procedure, without significant improvement. Consequently we decided on CBPG application every $48 \mathrm{~h}$. A fast improvement in PUs healing was observed since the first application of CBPG. The PU healed resulted in a scar after 53 and 50 days (Case 1 and Case 2, respectively) from development. In both cases, during CBPG treatment, no complications or infection were reported.

Recent evidence has suggested that treatment with CBPG could improve PU due to its potential effects reducing hospitalization time and care costs [14]. 
The antimicrobial activity of CBPG prevents the occurrence of infections creating a skin barrier, and, consequently, its complications. Moreover, studies have highlighted that CBPG has a hemostatic effect on the lesions and improves the healing process $[15,16]$.

The healing time of neonatal PU is not defined, so we cannot compare our result with standard treatment. However, neonatal PU treatment with CBPG seems safe and might be an alternative, potentially more successful option for the treatment of neonatal PU.

To our knowledge, this is the first report of CBPG as treatment of neonatal PU.

Based on our observations, CBPG treatment could be the first-line treatment of neonatal PU, reducing the healing time and infectious risks.

Long-term aesthetic and functional results (skin elasticity, scar retractions, skin discolorations) should be evaluated over time and requires further studies.

Author Contributions: Conceptualization, S.F., S.G. and A.Z.; Data collection and assembly, S.F. and A.Z. Data analysis and interpretation, S.F., S.G. and A.Z. Writing of manuscript, S.F., S.G., A.Z. and G.S. Critical review and revision of manuscript, S.G., R.C., S.V., L.P. and F.M. Submission of manuscript, S.F. and G.S. All authors have read and agreed to the published version of the manuscript.

Funding: This research received no external funding.

Institutional Review Board Statement: Not applicable.

Informed Consent Statement: Informed consent was obtained from all subjects involved.

Data Availability Statement: The data supporting the findings of this study are private due to patients' privacy, but they are available from the corresponding author.

Conflicts of Interest: The authors declare no conflict of interest.

\section{References}

1. García-Molina, P.; Alfaro-López, A.; García-Rodríguez, S.M.; Brotons-Payá, C.; Rodríguez-Dolz, M.C.; Balaguer-López, E. Neonatal pressure ulcers: Prevention and treatment. Res. Rep. Neonatol. 2017, 2017, 29-39. [CrossRef]

2. García-Molina, P.; Balaguer-López, E.; García-Fernández, F.P.; Ferrera-Fernández, M.D.L.; Ángeles, B.J.M.; Verdú, J. Pressure ulcers' incidence, preventive measures, and risk factors in neonatal intensive care and intermediate care units. Int. Wound J. 2018, 15, 571-579. [CrossRef]

3. August, D.L.; Edmonds, L.; Brown, D.K.; Murphy, M.; Kandasamy, Y. Pressure injuries to the skin in a neonatal unit: Fact or fiction. J. Neonatal Nurs. 2014, 20, 129-137. [CrossRef]

4. Visscher, M.; Taylor, T. Pressure Ulcers in the Hospitalized Neonate: Rates and Risk Factors. Sci. Rep. 2014, 4, 7429. [CrossRef] [PubMed]

5. Baharestani, M.M.; Ratliff, C.R. Pressure Ulcers in Neonates and Children. Adv. Ski. Wound Care 2007, 20, 208-220. [CrossRef] [PubMed]

6. Marcellus, L. Determination of Positional Skin-Surface Pressures in Premature Infants. Neonatal Netw. 2004, 23, 25-30. [CrossRef] [PubMed]

7. Piccin, A.; Di Pierro, A.M.; Canzian, L.; Primerano, M.; Corvetta, D.; Negri, G.; Mazzoleni, G.; Gastl, G.; Steurer, M.; Gentilini, I.; et al. Platelet gel: A new therapeutic tool with great potential. High Speed Blood Transfus. Equip. 2016, 15, $333-340$.

8. Kirmani, B.H.; Jones, S.G.; Datta, S.; McLaughlin, E.K.; Hoschtitzky, A.J. A meta-analysis of platelet gel for prevention of sternal wound infections following cardiac surgery. High Speed Blood Transfus. Equip. 2016, 15, 57-65. [CrossRef]

9. Suthar, M.; Gupta, S.; Bukhari, S.; Ponemone, V. Treatment of chronic non-healing ulcers using autologous platelet rich plasma: A case series. J. Biomed. Sci. 2017, 24, 16. [CrossRef]

10. Mohammadi, S.; Nasiri, S.; Mohammadi, M.; Mohammadi, A.M.; Nikbakht, M.; Panah, M.Z.; Safar, H.; Mostafaei, S.; Norooznezhad, A.H.; Soroosh, A.R.; et al. Evaluation of platelet-rich plasma gel potential in acceleration of wound healing duration in patients underwent pilonidal sinus surgery: A randomized controlled parallel clinical trial. Transfus. Apher. Sci. 2017, 56, 226-232. [CrossRef]

11. Perotti, G.; Stronati, M. Allogeneic platelet leucocyte-gel to treat occipital decubitus ulcer in a neonate: A case report. High Speed Blood Transfus. Equip. 2012, 10, 387-389. [CrossRef]

12. Parazzi, V.; Lavazza, C.; Boldrin, V.; Montelatici, E.; Pallotti, F.; Marconi, M.; Lazzari, L. Extensive Characterization of Platelet Gel Releasate from Cord Blood in Regenerative Medicine. Cell Transplant. 2015, 24, 2573-2584. [CrossRef]

13. Rosso, L.; Parazzi, V. Pleural tissue repair with cord blood platelet gel. High Speed Blood Transfus. Equip. 2014, 12, s235-s242. [CrossRef] 
14. Volpe, P.; Marcuccio, D.; Stilo, G.; Alberti, A.; Foti, G.; Volpe, A.; Princi, D.; Surace, R.; Pucci, G.; Massara, M. Efficacy of cord blood platelet gel application for enhancing diabetic foot ulcer healing after lower limb revascularization. Semin. Vasc. Surg. 2017, 30, 106-112. [CrossRef] [PubMed]

15. Tadini, G.; Guez, S. Preliminary evaluation of cord blood platelet gel for the treatment of skin lesions in children with dystrophic epidermolysis bullosa. High Speed Blood Transfus. Equip. 2015, 13, 153-158. [CrossRef]

16. Tadini, G.; Pezzani, L.; Ghirardello, S.; Rebulla, P.; Esposito, S.; Mosca, F. Cord blood platelet gel treatment of dystrophic recessive epidermolysis bullosa. BMJ Case Rep. 2015, 2015. [CrossRef]

17. Gelmetti, A.; Greppi, N.; Guez, S.; Grassi, F.; Rebulla, P.; Tadini, G. Cord blood platelet gel for the treatment of inherited epidermolysis bullosa. Transfus. Apher. Sci. 2018, 57, 370-373. [CrossRef] [PubMed]

18. Parazzi, V.; Lazzari, L.; Rebulla, P. Platelet gel from cord blood: A novel tool for tissue engineering. Platelets 2010, 21, 549-554. [CrossRef]

19. Available online: https:/ / www.npiap.com (accessed on 12 March 2021).

20. Rebulla, P.; Pupella, S.; Santodirocco, M.; Greppi, N.; Villanova, I.; Buzzi, M.; De Fazio, N.; Grazzini, G.; Argiolas, M.; Bergamaschi, P.; et al. Multicentre standardisation of a clinical grade procedure for the preparation of allogeneic platelet concentrates from umbilical cord blood. High Speed Blood Transfus. Equip. 2015, 14, 73. [CrossRef]

21. Mazzucco, L.; Balbo, V.; Cattana, E.; Borzini, P. Platelet-rich plasma and platelet gel preparation using Plateltex ${ }^{\circledR}$. Vox Sang. 2008, 94, 202-208. [CrossRef]

22. Longo, V.; Rebulla, P.; Pupella, S.; Zolla, L.; Rinalducci, S. Proteomic characterization of platelet gel releasate from adult peripheral and cord blood. Proteom. Clin. Appl. 2016, 10, 870-882. [CrossRef] [PubMed]

23. Manning, M.-J.; Gauvreau, K.; Curley, M.A. Factors Associated With Occipital Pressure Ulcers in Hospitalized Infants and Children. Am. J. Crit. Care 2015, 24, 342-348. [CrossRef] [PubMed]

24. Sorg, H.; Tilkorn, D.J.; Hager, S.; Hauser, J.; Mirastschijski, U. Skin Wound Healing: An Update on the Current Knowledge and Concepts. Eur. Surg. Res. 2017, 58, 81-94. [CrossRef] [PubMed] 